\title{
Estrategias de los trabajadores de empresas recuperadas en Argentina
}

\author{
Natalia Vanesa Hirtz ${ }^{*}$ \\ Marta Susana Giacone ${ }^{\star *}$
}

\begin{abstract}
Resumen
Las primeras empresas recuperadas (ER) en Argentina surgen en un momento histórico del ascenso de la lucha social y se consolidan durante el periodo de descenso de ésta. En aquel momento nacen diversas organizaciones con estrategias y tácticas propias, que se irán transformando frente a los nuevos contextos. En este trabajo analizamos el desarrollo de estas tácticas y estrategias; su impacto social, político y económico, así como sus límites, en el marco del contexto en el cual nacen y se desenvuelven. La información proviene de la exploración documental de información general de los movimientos de ER, la observación directa y la realización de entrevistas en profundidad.
\end{abstract}

\section{Palabras clave}

Empresas recuperadas, Organizaciones, Lucha, Autogestión, Gobernabilidad.

\section{Abstract}

The first recovered companies in Argentina appeared in a historic moment of social struggle and consolidated their movements as the struggle receded. From there, various organizations arose with their own tactics and their own strategies. We analyze, in this work, the development of these tactics and strategies, their social, political and economic impacts, as well as their limits, as the movement grew and developed. Information comes from documentary research of general information from the movement of recovered companies, from direct observation and in-depth interviews.

\section{Key words}

Recovered factories - Organization-Struggle - Governance - Self management.

Forma sugerida de citar: Hirtz, Natalia Vanesa y Giacone, Marta Susana. 2011. "Estrategias de los trabajadores de empresas en Argentina". Universitas 14. Enero/Junio. Pp $15-41$.

\footnotetext{
* Socióloga y Antropóloga, miembro del proyecto de investigación: "La estructura del Trabajo en la Argentina (encuesta obrera)"de la Secretaría de Ciencia y Técnica de la Universidad Nacional de Córdoba. nhirtz@ulb.ac.be.

** Profesora de Escuela de Enfermería de la Facultad de Ciencias Médicas de Universidad Nacional de Córdoba Argentina.msgiacone@hotmail.com.
} 


\section{Introducción}

Este trabajo forma parte de una investigación en curso que busca indagar el proceso de desarrollo de la lucha de los trabajadores de ER; su impacto social, político y económico, y sus límites, en el marco del contexto en el cual nacen (periodo de ascenso de luchas sociales) y se consolidan como movimiento (periodo de descenso de éstas).

La lucha de los trabajadores de ER emerge dentro de un ciclo de rebelión en Argentina. De acuerdo a las investigaciones realizadas por N. I. Carrera y M. C. Cotarelo, este ciclo de rebelión se desarrolla desde "diciembre de 1993 hasta la insurrección espontánea de diciembre de 2001", pero se extiende más allá de ese año (Cotarelo y Carrera, 2003: 1-2).

Los resultados presentados en este trabajo corresponden a la exploración documental de información general de los movimientos de ER; estudio de campo con observación directa y entrevistas en profundidad realizadas tanto a trabajadores de las ER Brukman y FaSinPat como a dirigentes del Movimiento Nacional de Empresas Recuperadas (MNER), Movimiento Nacional de Fábricas Recuperadas por sus Trabajadores (MNFRT) y la Federación Argentina de Cooperativas de Trabajadores Autogestionados (FACTA).

\section{Breve reseña histórica del ciclo de rebelión}

Frente a las luchas de clase, desatadas en distintos puntos del mundo durante los años sesenta y con la eclosión de la crisis del modelo económico de posguerra en 1974, el capitalismo lanza una ofensiva general para disciplinar a las masas trabajadoras y reestructurar el modelo productivo con el objetivo de recuperar tasas de ganancia. Para ello, se diseñan nuevas medidas que serán introducidas y generalizadas con la llegada al poder de Thatcher en Inglaterra y de Reagan en Estados Unidos. Dando origen a lo que más tarde serán conocidas como "políticas neoliberales".

El capital lanzará su ofensiva instaurando extremos mecanismos de represión para desarticular las luchas y allí donde estos pudieran resultar insuficientemente eficaces, acudirá a la implantación de dictaduras. Pero para lograr sus objetivos, el capital debe asegurarse no solo de instalar el temor, sino también 
la disciplina de las masas trabajadoras. Esto implicó la construcción de nuevos marcos ideológicos que justificaran la necesidad de sostener este modelo. Intelectuales y medios de comunicación serán rápidamente movilizados para asegurar la efectivización de estos instrumentos ideológicos.

El nuevo movimiento de la historia se presentará como un pasaje necesario e inevitable para poner fin a una sociedad que se caracterizaba como marcada por la rigidez, el arcaísmo y la uniformidad y avanzar en la construcción de otra en donde reinaran valores como la flexibilidad, la dinámica, la innovación, la libertad y el mercado.

Estas políticas, en Argentina, se consolidarán durante los años noventa, con la aplicación de los postulados del "Consenso de Washington", destinados a los países de América Latina e implementados a través de los organismos financieros internacionales. Con su aplicación, se experimentarán las nuevas medidas económicas que rápidamente se convertirán en programa general. Los puntos esenciales de esta propuesta son: racionalización del gasto público, reforma impositiva, tasas de cambio competitivas, liberalización del comercio internacional y de las inversiones extranjeras, privatizaciones y desregularización (Ramonet et al., 2009).

En Argentina se introdujeron fuertes recortes en el gasto público, impactando particularmente a sectores como salud, educación y seguridad social. También se recurrió a la privatización y/o tercerización masiva de empresas y servicios públicos, se sobrevaluó la moneda, se revisó el código de impuestos y profundizó la apertura del mercado.

Si bien estas medidas se presentaron como modelo de desarrollo que favorecía los intercambios comerciales y financieros, acabaron por profundizar el déficit comercial, ${ }^{1}$ llevando al cierre a miles de empresas que al no ser lo suficientemente competitivas terminaron por desaparecer, aumentando los despidos que se sumaban a los realizados por las empresas privatizadas. ${ }^{2}$

1 Entre 1990 y 1998, las importaciones se multiplicaron por siete, mientras que las exportaciones se duplicaron (Ferreres, 2005: 593).

2 Entre 1998 y 2002, el déficit de creación de empresas, en relación a la desaparición, fue de 48.000 empresas, lo cual se tradujo en una pérdida de 431.000 empleos (Castillo et al, 2006: 43). 
Para enfrentar la competencia de los mercados externos, con una moneda alta, el capital acudió a la reducción de los salarios reales. ${ }^{3}$ Esta disminución del poder adquisitivo de los trabajadores terminó por crear una contracción de la demanda interna.

Los mecanismos privilegiados tradicionalmente para ajustar los costos laborales (disminución del salario real mediante la inflación) cambiaron frente a la estabilidad monetaria. El capital recurrirá a disminuir estos costos por la vía de la flexibilidad laboral (Godio, 2000: 1247).

Se implementaron reformas laborales que apuntaron a aumentar la productividad y la intensidad del trabajo y a instalar mecanismos que permitieran reducir y controlar la conflictividad social. ${ }^{4}$

Las nuevas modalidades de organización del trabajo exigían ampliar y reducir la planta de personal con rapidez (según las necesidades del mercado), contratar personal en el momento que crecía la demanda del producto y despedirlo - sin que implique costos - cuando se contraía.

Sin embargo, estas medidas no se mostraron eficaces para remontar la economía nacional y en 1998 Argentina entró en recesión. En 2002, la tasa de desempleo llegó al 24,26\%, el nivel más alto de la historia argentina (Ferreres, 2005: 466).

Frente a la implementación de estas reformas las acciones llevadas a cabo por la Central General de Trabajadores (CGT) durante el Gobierno menemista, ${ }^{5}$ se limitaron a defender sus garantías corporativas, dejando en segundo plano las reformas laborales (Etchemendy y Palermo, 1998).

3 A partir de la última dictadura militar, el salario real de los trabajadores ha ido en descenso progresivo. Tomando como base (100) el año 1975, el índice de salario real era de 38,5 en 1999 (Instituto Nacional de Estadística y Censos, 2000).

4 Se trató de reformas estructurales que conjuntamente con las medidas ya mencionadas apuntaban a ganar la confianza financiera internacional y propiciar la reconversión productiva; prometiendo después de un primer impacto regresivo sobre el mercado de trabajo, un crecimiento continuado del empleo y los ingresos. Para paliar los efectos negativos de la reestructuración y potenciar los aspectos positivos de la misma, los cambios económicos fueron acompañados de variados programas sociales.

5 Carlos Menem fue Presidente de la nación desde el año 1989 hasta 1999 por el Partido Justicialista (Partido continuador del Partido Peronista, fundado por Juan Domingo Perón en 1947). Este gobierno se plegó a los principios del Consenso de Washington, introduciendo las reformas descritas más arriba. 
Esta conducta del aparato sindical llevó a un quiebre político de la "columna vertebral" del peronismo, forjando nuevas formas de organización de los trabajadores. Se creó la Central de Trabajadores Argentinos (CTA), surgieron delegaciones y gremios combativos y luchas autónomas de la estructura sindical.

El descontento se acentuó y a las movilizaciones obreras se sumaron otras organizaciones como la de los trabajadores desocupados (conocidos como grupos piqueteros), las asambleas barriales y las primeras ER.

Las huelgas, los cortes de ruta, las movilizaciones y las ocupaciones de fábricas se multiplicaron, desatando uno de los periodos de lucha más importante de las últimas décadas de la historia argentina, encontrando su punto máximo en los enfrentamientos del 19 y 20 de diciembre de 2001.

Ante la intensidad de la lucha, el 19 de diciembre, el presidente de la nación, Fernando de la Rúa, declara el estado de sitio en todo el país. Pero contrariamente a lo esperado por el poder gubernamental, este anuncio desencadena una movilización popular que se enfrentará durante dos días contra las fuerzas del orden, en reacción al estado de sitio y exigiendo la renuncia del gobierno. La represión no se hizo esperar, dejando un saldo de al menos 35 muertos, un millar de heridos y más de 3.500 detenidos (según el Centro de Estudios Legales y Sociales, CELS).

El 20 de diciembre, Fernando de la Rúa, debió renunciar a su cargo; sucedido por tres presidentes provisionales incapaces de estabilizar la situación, el 2 de enero de 2002, el Congreso de la Nación nombra a Eduardo Duhalde, quien concluye el mandato presidencial.

La lucha no logró traducirse en alternativas políticas y la burguesía fue la que consiguió encontrar una solución capitalista a la crisis.

Este ciclo de rebelión se caracterizó por la presencia y el fortalecimiento de organizaciones que apuntan a la "autonomía". Los grupos piqueteros, los clubes de trueque, las asambleas de barrio y las empresas recuperadas se constituyeron en los emblemas de estas luchas. Y aunque cada uno de estos movimientos reclamó reivindicaciones particulares, todos ellos expresaron una puesta en cuestionamiento al 'control' de las elites gubernamentales y económicas sobre el destino de la población.

La recuperación de empresas formó parte de estas formas de lucha y se convirtió en un nuevo instrumento de los trabajadores para responder a la crisis. 
Las primeras recuperaciones surgieron a finales de los años noventa como fenómenos aislados. En 2001, estas experiencias se multiplicaron rápidamente y los trabajadores comenzaron a organizarse en un momento histórico de ascenso de luchas. Pero las diferencias políticas incidieron sobre las estrategias y tácticas a seguir, llevando a la conformación de diversas organizaciones de ER.

Actualmente existen alrededor de 200 ER que no solo se mantienen en pie con el paso del tiempo (salvo algunas excepciones), sino que también han logrado aumentar el número de sus trabajadores.

Si bien a partir de 2004 la recuperación de nuevas empresas se realizó de manera pausada, desde finales de 2008 la cifra de nuevas recuperaciones comienza a aumentar aceleradamente. Indicador de que frente a la crisis actual la recuperación se impone como potente instrumento de lucha de los trabajadores contra la pérdida del empleo.

\section{Reseña histórica de las ER}

La lucha por el control de los medios de producción tiene antiguos antecedentes en la historia del movimiento obrero, encontrando su origen en la constitución del sistema de producción capitalista. ${ }^{6}$

Así, en su obra sobre la creación de la clase obrera en Inglaterra, E. Thompson (1968) desarrolla la manera en que estas luchas se encarnaron originalmente en los artesanos (convertidos en obreros), nostálgicos de la época en la que el modo de producción se basaba en las sociedades de oficios.

El modo de producción capitalista implicará una separación entre producto y productor; entre trabajadores (que solo poseen como medio de producción su propia fuerza de trabajo) y capitalistas (propietarios de los medios de producción). La ocupación de los medios de producción por sus trabajadores expresa la lucha contra este tipo de separación y por el control de los trabajadores sobre el proceso de producción. Control que en el sistema capitalista es realizado por el patrón y/o sus administradores.

$6 \quad$ Ya, en 1819, se observan luchas de esta naturaleza encarnadas por los obreros ingleses del tabaco, quienes luego de realizar once semanas de huelga, comenzaron a producir por su cuenta (Mandel, 1970:7). 
Estas luchas se desarrollarán a lo largo de la historia con más o menos intensidad y bajo formas y orientaciones políticas diferentes, pero todas personificarán el rechazo de la dominación del capital sobre el trabajo.

En Argentina las primeras ocupaciones de fábricas se desarrollaron en los años cincuenta, afirmándose como poderoso instrumento de lucha durante los conflictos obreros de los años sesenta y setenta.

Luego de dos décadas de repliegue y desarticulación del movimiento obrero, las ocupaciones de fábricas resurgieron durante los años noventa profundizando sus medidas. A partir de la recuperación de este instrumento, los trabajadores avanzaron creando uno nuevo: la recuperación de las empresas.

Las primeras recuperaciones emergieron como fenómenos aislados. De manera general surgen de un conflicto que comienza con el proceso de crisis de la empresa. Para los trabajadores este proceso de crisis significa la disminución o el no pago de los salarios, la pérdida de los beneficios sociales y despidos. Esta situación abre un conflicto entre trabajadores y empresarios que desemboca en la ocupación de la empresa.

La ocupación puede durar varios meses sin que se encuentre una solución a las demandas de los trabajadores que apuntan a la reapertura de la empresa. Mientras tanto, estos no tienen acceso a salarios ni indemnizaciones por despido, situación que los lleva a relanzar la producción de la empresa para poder hacer frente a sus necesidades de subsistencia.

Así, en su inicio, la lucha de los trabajadores no apunta al control de la producción sino a la protección de sus fuentes de ingreso. Sin embargo, el proceso desarrollado para lograr este objetivo los induce a tomar en sus manos el control de la producción.

Durante el proceso de lucha contra el cierre de la empresa, su ocupación y puesta en funcionamiento, se crearán nuevas solidaridades entre trabajadores y se forjarán formas de organización más horizontales. ${ }^{7}$

$7 \quad$ La solidaridad no siempre se limita al ámbito de la fábrica. La mayoría de estas empresas fueron recuperadas entre los años 2001 y 2003, momento histórico de lucha en Argentina en el que los trabajadores de ER tuvieron notoria participación uniéndose a la lucha de otros sectores. Así se conformaron coordinadoras en las que participaban grupos piqueteros, trabajadores y estudiantes. 
Al retomar la producción de la empresa los trabajadores la gestionarán y organizarán el trabajo empleando los mismos métodos que aprendieron en la lucha: la discusión y la toma de decisiones mediante la asamblea general.

El proceso de recuperación induce no solo a la creación de formas de organización más horizontales sino que también implica un avance en el cuestionamiento del principio inviolable de la propiedad privada y favorece la construcción de solidaridades, en un contexto en que las nuevas formas de organización del trabajo introducían mecanismos de competencia, promoviendo estrategias $\mathrm{y}$ vivencias profundamente individualistas.

Sin embargo, los trabajadores no pueden hacer funcionar estas empresas por mucho tiempo sin encontrar una cobertura legal.

La creación del MNER y de la Coordinadora de Fábricas Ocupadas y Trabajadores en Lucha, marcaron dos estrategias diferentes para responder a esta situación: la expropiación de la empresa y donación en comodato a los trabajadores previamente conformados en cooperativa de trabajo, y la estatización bajo control obrero.

Estas estrategias traducen distintas orientaciones políticas. La primera expresa la búsqueda de una transformación social a partir de la creación y el fortalecimiento de empresas autogestionadas por los trabajadores; la segunda apunta a una transformación social a partir de la unión y la lucha de los trabajadores sin limitarse al ámbito específico de las ER, reivindicando su identidad de clase trabajadora.

\section{Conformación de las organizaciones de empresas recuperadas ${ }^{8}$}

Durante el año 2001, la recuperación de empresas se multiplicaron y los trabajadores comenzaron a coordinar acciones.

8 Existen múltiples organizaciones de ER, en esta instancia solo abordaremos aquellas de mayor relevancia política y social. 
En octubre de ese año, los obreros de la ER IMPA ${ }^{9}$ convocaron a una reunión en la que participaron tanto ER como también la Federación de Cooperativas Portuarias, la Unión de Trabajadores Desocupados de Santa Fe y la Federación de Cooperativas de Trabajo.

El objetivo de esta reunión fue conformar un movimiento que apunte a encontrar una solución jurídica para las ER, reforzarlas económicamente y favorecer la multiplicación de estas experiencias. Buscando también fortalecer el desarrollo de una economía solidaria. ${ }^{10}$

De este encuentro surgirá el MNER, conformado por la mayoría de las ER presentes. El objetivo consistía en integrar todas las iniciativas de recuperación sin importar las formas societarias que estas adoptaran. La prioridad se puso en la recuperación de las empresas. Considerando que la conformación en "cooperativa" es un medio necesario para la recuperación, pero no un fin en sí mismo. ${ }^{11}$ Por este motivo decidieron constituir un movimiento específico, por fuera de las federaciones de cooperativas.

La conformación en cooperativa de las ER será adoptada como una estrategia que apunta a facilitar el proceso de recuperación. La táctica se orientará a recuperar los puestos de trabajo, la economía productiva nacional y a promover la implementación de formas democráticas de gestión al interior de las empresas.

Al mismo tiempo, en Neuquén los trabajadores de Cerámica Zanón habían ocupado la fábrica y comenzaban a organizar el relance de la producción apoyados por un sindicato clasista y combativo que había forjado a sus militantes en esta fábrica. La lucha de estos trabajadores había comenzado unos años antes frente a la precarización de las condiciones de trabajo impuestas por sus empresarios. Los trabajadores se movilizaron consiguiendo sus reivindicaciones, pero también lograron recuperar la dirección de un gremio que durante muchos

$9 \quad$ IMPA fue una de las primeras fábricas recuperadas por sus trabajadores en el país. Esta metalúrgica era una cooperativa con un Consejo de Administración centralizado. En 1998, los trabajadores retomaron la producción en sus manos, restituyendo al antiguo Consejo de Administración y declarando el principio de soberanía de la asamblea general.

10 Véase el Acta de reunión reproducida en Rebón. J. (2004: 144-146).

11 Entrevista realizada a Ignacio Saavedra, ex-miembro del MNER. Diciembre, 2004. 
años había estado en manos de un grupo identificado por los trabajadores como 'corrupto' y 'traicionero'.

Dos meses más tarde en Capital Federal, las trabajadoras de la textil Brukman entran en conflicto. La mayoría de ellas no tenía experiencia de lucha y fueron empujadas a ocupar la fábrica frente a la situación extrema (...) "no tener plata para comprar el pasaje de regreso a casa" ${ }^{12}$ ya que hacía varios meses que no cobraban sus salarios.

Rápidamente se estableció un lazo de fraternidad entre estas dos fábricas que los llevó a crear una Coordinadora de trabajadores en lucha. A comienzos de 2002, convocaron al primer encuentro Nacional de Fábricas Ocupadas y Trabajadores en Lucha.

La conceptualización particular del proceso como "fábricas ocupadas y en lucha" ilustra la orientación política tomada por estos trabajadores, apuntando al refuerzo de la lucha obrera sin limitarse a la recuperación de la fábrica. De hecho, estos trabajadores adoptarán como estrategia inmediata frente al cierre de sus fábricas el reclamo de "Estatización bajo control obrero". Diferenciándose así de la estrategia adoptada por el MNER que apostaba a la conformación de cooperativas u otras formas societarias que facilitaran el traspaso de propiedad de la empresa a sus trabajadores.

Esta Coordinadora no buscaba conformar un movimiento específico sino crear un frente de unidad para la lucha. Participarán en sus encuentros: grupos piqueteros, gremios combativos, trabajadores en lucha, asambleas de barrio, organizaciones de derechos humanos y partidos políticos revolucionarios.

\section{Descenso de la lucha y fragmentación de los movimientos sociales}

La Coordinadora de Fábricas Ocupadas y Trabajadores en Lucha no subsistirá mucho tiempo.

Su desarticulación respondió principalmente a un contexto en que las luchas sociales comenzaron a replegarse para dejar lugar a un nuevo periodo

12 Entrevista realizada a Ester Valdez, obrera de Bruckman. Abril, 2007. 
de gobernabilidad que, en un principio, se impuso por la fuerza y, luego, buscó consolidarse por la vía de la institucionalización de ciertos reclamos y demandas obreras. En este proceso la reivindicación de estatización bajo control obrero quedó relegada. Sin embargo, su corta existencia marcará un punto importante en la historia obrera, convirtiendo a las empresas que la conformaban en emblemas de la lucha, por su combatividad, presencia y solidaridad con las luchas libradas por otros sectores explotados.

La concepción sobre la cual la coordinadora se constituyó es diferente a la planteada por el MNER que apuntaba a la conformación de un movimiento capaz de reforzar la recuperación de las fábricas, en el cual:

... Ni siquiera exigimos a los compañeros que estén en el resto de las movilizaciones del movimiento (...) Vamos y brindamos nuestra solidaridad en serio a los trabajadores. Lo único que les pedimos es que cuando estén bien ayuden a otros compañeros. ${ }^{13}$

Esta concepción implica la adhesión de ER sin necesidad de participación activa en sus procesos de decisión, lucha y conformación. Posición que coloca al movimiento en un papel asistencialista hacia las ER. El riesgo de esta política es que termina por convertir a sus dirigentes en únicos actores del movimiento, al mismo tiempo que posiciona a los trabajadores en asistidos. Situación que terminó transformando al movimiento en una suerte de organización administradora (jurídica, política y económica) de lo recuperado por los trabajadores.

El MNER se constituyó con estos objetivos y expresando una alianza entre sectores independientes, socialistas y peronistas.

Esta alianza no perduró mucho tiempo y terminó produciendo rupturas al interior del movimiento.

La primera gran ruptura se dio en plena campaña electoral (2003). La adhesión de ER al MNER no había dejado de incrementarse hasta ese año, momento

13 Entrevista realizado por Magnani E. (2003: 61) a Eduardo Murúa, ex- Presidente del MNER. Agosto, 2003 . 
en que Luis Caro $^{14}$ abandona el movimiento para crear su propia organización: el Movimiento Nacional de Fábricas Recuperadas por los Trabajadores (MNFRT), que cooptará casi la mitad de las ER que integraban el MNER.

El MNFRT se constituyó como Organización No Gubernamental (ONG) "apolítica", asumiendo como único objetivo "recuperar el trabajo (...) medio indispensable para satisfacer nuestras necesidades espirituales y materiales" (MNFRT, 2003). ${ }^{15}$

Su orientación "política" puede resumirse de manera general en limitar estos procesos de lucha a la recuperación de empresas como alternativa de los trabadores frente al desempleo, y para mejorar sus condiciones económicas y de trabajo. Diferenciándose así del MNER, que ambicionaba un cambio social a partir de la multiplicación de la recuperación de empresas. Cambios que para algunos se limitaban a la recuperación de la producción nacional y del trabajo "digno" y para otros implicaba además transformaciones en la construcción de la subjetividad de los trabajadores.

La creación de esta nueva organización responderá a la orientación que tomará una gran parte de las fábricas recuperadas, frente a un contexto de repliegue de las luchas en que los trabajadores de las ER se limitarán a mantener y reforzar lo "recuperado", consolidando jurídica y económicamente sus empresas.

La segunda ruptura fatal para el movimiento sucederá en 2006 cuando algunos de sus máximos referentes crean una fracción, conformando un nuevo movimiento: la Federación Argentina de Cooperativas de Trabajadores Autogestionados (FACTA) con la cual partirá la mayoría de las empresas que integraban el MNER.

Los conflictos en el interior del MNER habían comenzado en 2005, cuando la metalúrgica recuperada IMPA (pionera de este movimiento) comenzó a atra-

14 Luis Caro era abogado del MNER y uno de sus dirigentes máximos. Fue una suerte de talón de Aquiles para la organización, ya que gracias a sus contactos políticos logró encontrar algunas soluciones transitorias o definitivas a las necesidades inmediatas de los trabajadores de ER. Soluciones analizadas más adelante.

15 En este boletín realizado por el MNFRT, se termina agradeciendo a "los funcionarios públicos que se comprometen con la recuperación de la fábricas..." y llamando la atención sobre posibles plagios: "queda terminantemente prohibida la reproducción total o parcial del material publicado sin mencionar el origen", enfatizando así, la marcada connotación legalista de esta ONG. 
vesar por una de sus peores crisis, sin poder responder al pago de sus deudas. A esto se sumó una crisis en el seno de la cooperativa, que puso en cuestionamiento su dirección y produjo una ruptura entre trabajadores que terminaron conformando tres grupos: uno que acudió a Luis Caro para que propusiera a "allegados a él" que invirtieran en la cooperativa; otro grupo defendía la dirección de Robledo y Murúa ${ }^{16}$; el tercero acudió a otros dirigentes del MNER que comenzaban a encontrar desacuerdos con el presidente del movimiento y que, un año más tarde, conformaron FACTA.

Las denuncias de corrupción y manejos oscuros del entonces presidente del MNER se sumaban a algunos desacuerdos políticos que habían surgido unos meses antes, cuando los trabajadores de IMPA, con Eduardo Murúa a la cabeza, se movilizaron para exigir al Gobierno la obtención de un crédito a través del Banco de la Nación. Murúa y Robledo decidieron sobrepasar los canales institucionales que este movimiento había logrado establecer con el poder nacional, llamando a la movilización contra las políticas de un Gobierno en las que algunos dirigentes del MNER participaban o estaban fuertemente vinculados. ${ }^{17}$ Este hecho acentuó las divergencias en el seno del movimiento sobre las formas de relacionarse con el Gobierno, situación que culminó en la conformación de FACTA. La constitución de esta nueva Federación es concebida como...

Una herramienta más para unir a un sector de la economía, en la cual las ER son parte integrante pero no es todo. Hay emprendimientos sociales, cooperativas de trabajo, las cuales tienen que agruparse en un movimiento más amplio. La idea es comenzar a plantear un gran movimiento de economía social. ${ }^{18}$

16 Eduardo Murúa, era presidente de IMPA y del MNER. Guillermo Robledo, era vicepresidente de IMPA y dirigente importante del MNER.

17 Como por ejemplo, Diego Kravetz, quien en ese entonces era diputado del Frente para la Victoria (el partido de N. Kirchner) o Francisco Gutiérrez quien fue diputado desde 2005 de este mismo partido y desde 2007 es intendente del Partido de Quilmes por el Polo Social, asociado políticamente al Frente para la Victoria. Al asumir la Intendencia, nombró a Guillermo Robledo como Secretario de Desarrollo Económico Local, Producción y Empleo. 
De esta manera ya no solo el proceso de lucha de los trabajadores se disuelve en el proyecto de ER, sino que éstas se diluyen en un proyecto de "economía social". Así la declaración de principios de esta nueva Federación concluye su presentación diferenciándose de las luchas que dieron origen al MNER: "porque no somos parte de lo que fue sino de lo que será" (FACTA, 9/12/2006).

Para comprender el proceso por el cual se crean estas fracturas y las nuevas estrategias y tácticas que se desprenden de ellas, debemos analizar no solo los procesos jurídicos y políticos de esta lucha sino también los económicos.

\subsection{Procesos políticos y jurídicos de la lucha de los trabajadores de ER}

El mecanismo reivindicado por los trabajadores, tanto para la estatización como para la cooperativización de una empresa, es la expropiación.

Para tramitar la expropiación cada ER tiene que presentar un proyecto de ley ante los poderes legislativo y ejecutivo. El poder legislativo debe votar la Ley que declara la "utilidad pública" del bien a expropiar. Votada la Ley el poder ejecutivo debe autorizar la expropiación y presentarla al juez que dirige el pleito de la quiebra de la empresa, quien fijará las modalidades de utilización del bien expropiado.

La obtención de la expropiación depende fuertemente de las voluntades políticas de los poderes gubernamentales. Dependencia que limita la autonomía y el campo de acción de los trabajadores, obligándolos a distanciarse progresivamente de sus reivindicaciones más radicales para evitar tensiones que entorpezcan la obtención de sus objetivos más urgentes. ${ }^{19}$

Mientras se tramita el pedido de expropiación los trabajadores deben encontrar soluciones intermedias para evitar el desalojo. Una de las soluciones jurídicas transitorias que se impuso como estrategia dominante, consistía en recurrir al artículo 190 de la Ley de Quiebras.

19 El presidente del MNFRT, Luis Caro, explica: “90\% de la solución de los conflictos tiene que ver con el convencimiento de los trabajadores y el resto es más estratégico y no solo jurídico sino que también depende de como te llevas con los políticos." (Entrevista a Luis Caro. Diciembre, 2004). 
Fruto de la lucha de los trabajadores de todas las ER, en abril de 2002 el MNER obtuvo durante el gobierno interino de Eduardo Duhalde la incorporación de este artículo, que concede el derecho a los trabajadores de solicitar la continuidad de la explotación de la empresa hasta el momento en que esta sea liquidada. Para acceder a este derecho los trabajadores deben crear una cooperativa.

Modificando la Ley de Quiebras e introduciendo la exigencia de la conformación de una cooperativa para poder acceder a la administración de la empresa, el Gobierno nacional estableció un mecanismo que legaliza una cierta forma de accionar, al mismo tiempo que penaliza severamente otras formas que no se encuentren integradas en las establecidas por la Ley. Esta penalización es justificada y legitimada gracias a la existencia de este nuevo marco legal que impone la solución para la recuperación de la empresa. Este proceso de institucionalización potencializó las tensiones existentes entre las estrategias a emplear y las tácticas a sostener, favoreciendo la desarticulación de los trabajadores.

El caso de Brukman fue un ejemplo disciplinador para todas las experiencias posteriores y terminó con la desarticulación de la Coordinadora de Fábricas Ocupadas y en Lucha.

El 17 de abril de 2003, unos 300 efectivos policiales arremetieron brutalmente desalojando a las trabajadoras de la fábrica. El 21 de abril (seis días antes de las elecciones presidenciales) miles de manifestantes intentaron recuperar la fábrica, la policía desató una represión brutal dejando un saldo de varios heridos y arrestados.

Durante el periodo de preparación electoral se observó una enorme escala represiva de los movimientos sociales. Brukman no fue un caso aislado. Los ataques hacia las organizaciones políticas y sociales eran permanentes y se fueron acentuando a medida que las elecciones se aproximaban; indicando la intención de controlar o hacer desaparecer los movimientos sociales antes de las elecciones para dejar el campo abierto a la instalación de una nueva 'gobernabilidad'.

La escalada de represión se aceleraba frente a un contexto en el que los movimientos sociales comenzaban a sufrir rupturas internas acentuadas por el proceso electoral, produciendo realineamientos políticos y creando conflictos en el interior de varias organizaciones que terminaron por desarticular la unión 
construida en la lucha. Un ejemplo de esto fue el caso del MNER que terminó con la fracción y la conformación del MNFRT. ${ }^{20}$

Por su parte las trabajadoras de Brukman, luego de haber pasado nueve meses fuera de la fábrica, lograron obtener su expropiación. Pero si en un principio las trabajadoras exigían la estatización bajo control obrero, nueve meses sin poder acceder a su fuente de trabajo fueron más que un escarmiento para que aceptaran conformarse en cooperativa de trabajo integrándose al MNFRT, luego de que el abogado y presidente de este movimiento, Luis Caro, obtuviera rápida y eficazmente la expropiación.

El retorno a la fábrica significó no solo que las trabajadoras aceptaran las condiciones establecidas por la Ley sino también un repliegue político de la lucha. El abogado Luis Caro explica así su preocupación y el esfuerzo que tuvo que realizar para que las trabajadoras comprendieran la necesidad de este proceso:

La primera vez que fui a hablar con los obreros de Brukman, hacía 5 meses que estaban en la carpa. Yo les dije: "Vengo para ayudarlos a entrar. Pero para eso a este conflicto hay que despolitizarlo!"... "Yo les pedía por favor a los partidos de izquierda entender que esto es profesional, es como si viene una persona y dice 'Doctor opéreme del corazón. Y yo soy dermatólogo. No te puede operar un dermatólogo' (...) El tema de despolitizar es que vos tenés que meterte dentro del contexto. Nosotros, ¿qué queremos?: ¿Que se cambie la estructura social de la Argentina o queremos entrar a la fábrica? (...) Esto es puramente alimenticio. ${ }^{21}$

20 Uno de los argumentos por los que el MNER explicó el quiebre con Luis Caro, fue su presentación como intendente en la misma lista electoral en la que se presentaba Aldo Rico, ex coronel del Ejército que encabezó un alzamiento militar en 1987 y 1988 contra el Presidente Raúl Alfonsín en reacción al juicio que había condenado a los principales líderes de la dictadura militar (1976-1983). Por su parte Caro, consideraba que el MNER era demasiado "político" y que "nosotros no buscamos un cambio político, nosotros queremos trabajar"(Entrevista. Diciembre, 2004). 
La represión, la desesperación frente a la pérdida de trabajo y la desarticulación de los movimientos sociales que acontecieron durante los nueve meses en que las trabajadoras debieron acampar frente al Congreso para exigir la expropiación de la fábrica, terminaron por hacer propias las palabras con las cuales Luis Caro describió su suerte:

¿Qué pasó con Brukman?, ellos no aceptaron la propuesta de la cooperativa. Dijeron: "Noooo, nosotros queremos control obrero... que esto y que aquello". Y bueno, ¿qué paso? Los desalojaron! ${ }^{22}$

De manera explícita Luis Caro justifica la violencia estatal y la penalización que se efectiviza frente a reivindicaciones diferentes a las dispuestas y establecidas por el poder. Las tensiones existentes entre las estrategias a emplear y las tácticas apuntadas por los trabajadores se terminan resolviendo al imponerse la solución técnico-legal de la recuperación por sobre el conflicto político. Se justifica la violencia estatal debido a la politización del movimiento mientras se potencia la desarticulación de la solidaridad entre los trabajadores.

Para los trabajadores de las ER que reivindicaban la estatización bajo control obrero, esta posición expresaba el rechazo a la gestión empresarial que podía llegar a implicar la conformación de una cooperativa, y a los esfuerzos que los trabajadores deberían realizar para consolidarla económicamente dentro del mismo mercado en el cual estas empresas ya habían sido expulsadas.

La estatización de la empresa permitiría a los trabajadores distanciarse de las exigencias de rentabilidad del mercado, para poder centrar sus esfuerzos no en la competencia de mercado sino en la solidaridad obrera, tanto al interior como al exterior de la fábrica.

Sin embargo, los trabajadores debieron adaptarse en un contexto de repliegue de lucha social y aceptar la estrategia dominante para la recuperación.

$22 \quad$ Ibíd. 
La llegada al poder en el 2003 de Néstor Kirchner inaugurará un nuevo ciclo de gobernancia ${ }^{23}$ en Argentina, consolidando nuevas formas de subordinación de los movimientos sociales. ${ }^{24}$

Poco tiempo después de haber comenzado su mandato el gobierno de Kirchner, ${ }^{25}$ logró gran legitimación de la población contando con el apoyo de direcciones sindicales, intelectuales progresistas, movimientos sociales y organizaciones de derechos humanos, afianzando la resolución capitalista de la crisis.

Esta buena gobernancia consigue desplazar la centralidad de los movimientos sociales y reposicionar al Estado como actor central y representante de la lucha contra la 'derecha neoliberal', lo cual justifica el 'apoyo debido' de los movimientos sociales.

De acuerdo con Zibechi, (2009:7), para 'crear Estado', las nuevas formas de dominación "buscan neutralizar o modificar las redes y las formas de solidaridad, reciprocidad y ayuda mutua creadas por los de abajo para sobrevivir al modelo. Una vez desaparecidos los vínculos y saberes que les aseguran autonomía, pueden ser controlados con mayor facilidad".

En las ER el poder estatal institucionalizó el modo en que los trabajadores debían proceder para recuperar la empresa por medio de la conformación en cooperativa, para poder acceder a la continuación temporaria de la explotación de la empresa mientras se negocia la expropiación asumiendo el pago de la indemnización. Consecutivamente se crearon nuevos instrumentos para condicionar el funcionamiento interno de gran parte de estas cooperativas. El

23 Hacemos referencia al concepto de gobernancia desarrollado por los "programas de ajuste estructurales" impuestos por los organismos financieros internacionales. La buena gobernancia, es considerada como un conjunto de principios de buena gestión que implican una base para la legitimidad del poder. La "democracia representativa" deslegitimada debe ser completada por la "democracia participativa", por el "empowerment" de la sociedad civil. Con respecto a los movimientos sociales, la buena gobernancia significa, según estos preceptos, la cooperación entre movimientos sociales y Estado (Manor et all., 1999).

24 El gobierno interino de Duhalde instaura los nuevos mecanismos de dominación (por ejemplo, la represión selectiva hacia algunos movimientos y la distribución de subsidios a otros). Sin lograr una buena gobernancia, este gobierno inaugurará un nuevo ciclo político que será consolidado por su sucesor.

Al hablar del gobierno, hacemos referencia a los múltiples organismos estatales que lo componen y no solo a la figura de su presidente. 
Programa Nacional de Promoción y Asistencia al trabajo Autogestionado y la Microempresa, creado en el 2004 por el Ministerio de Trabajo, es un claro ejemplo de las formas en que el Gobierno promueve la conformación de una estructura jerárquica de las relaciones en el seno de las cooperativas.

Para acceder a este programa, los trabajadores deben presentar un proyecto de trabajo e inscribirse en el Registro de Unidades Productivas Autogestionadas por los trabajadores. Este Registro apunta a asesorar y capacitar a los trabajadores.

El proyecto por el cual se solicita subsidio tiene que ser evaluado y llevado a cabo por funcionarios del Ministerio de Trabajo, que forman a los miembros del Consejo Administrativo de la cooperativa para que apliquen correctamente las recetas de gestión y de administración empresarial.

De esta manera se imponen formas de gestión reguladas diferentes a las que los trabajadores lograron desarrollar, se capacita a ciertas personas y se excluye a otras del ámbito de los conocimientos necesarios para llevar a cabo este tipo de gestión. Al concentrarse el conocimiento en pocas manos, se termina conformando un grupo de trabajadores que se especializa en la administración y otro que se dedica exclusivamente a ejecutar el trabajo manual. Induciendo a la destrucción de saberes compartidos y construidos colectivamente sobre formas de organización y de gestión del trabajo.

\subsection{Procesos económicos de las ER}

Si estos mecanismos de control y de institucionalización logran imponerse, no es solamente porque los trabajadores deben enfrentar la "justicia" para obtener el traspaso de propiedad de la empresa, sino también porque este traspaso implica la consolidación económica de la empresa dentro del mercado capitalista. ${ }^{26}$

En el capitalismo, las empresas buscan permanentemente introducir nuevos métodos que les permitan aumentar la productividad y la intensidad de trabajo para acrecentar sus ganancias. Las empresas que aplican estas innovaciones logran disminuir sus costos de producción, para

26 La mayoría de ER se dedican a la producción, por lo tanto centraremos nuestro análisis en las fábricas. 
obtener una tasa de plusvalía excedentaria, más importante que la de la competencia (industrias pertenecientes al mismo sector).

La competitividad entre capitalistas los induce a eliminar del precio de venta de sus mercancías, al menos una parte de esta plusvalía anormal, ya que incluso renunciando a una parte de la plusvalía estos capitalistas logran obtener una tasa normal de ganancia. Progresivamente estas innovaciones se generalizan en el resto de las fábricas, induciendo a una nueva igualación de las tasas de ganancia.

Las empresas que no tienen acceso o que no aplican estas innovaciones son excluidas de esta igualación y quedan expuestas a su desaparición. ${ }^{27}$ El gran capital termina arruinando y absorbiendo estas empresas que no resisten a la competencia.

Las ER no pueden existir por fuera del mercado. Los trabajadores pueden conformarse con una tasa de ganancia inferior a la tasa de ganancia general, ya que no hay en estas empresas un propietario capitalista que se apropie de una parte de la plusvalía para su consumo improductivo. Pero los trabajadores deben asegurarse una tasa mínima de ganancia para garantizar su 'consumo necesario' (para su mantenimiento y reproducción) y poder asegurar la reproducción de las mercancías; es decir, invertir una parte del beneficio en medios de producción necesarios para producir nuevas mercancías. ${ }^{28}$

Una de las mayores dificultades que encuentran estas cooperativas para poder garantizar la tasa mínima de ganancia, es que no disponen de grandes volúmenes de capital para invertir en nuevas tecnologías que les permitan aumentar la productividad del trabajo. El acceso al crédito es prácticamente imposible para estos trabajadores que al no ser propietarios de la empresa no tienen garantías para ofrecer. Solo una vez que hayan finalizado el pago de la indemnización de expropiación (o de la compra de la empresa) podrán utilizar la empresa como garantía para acceder al crédito. Entre tanto, los trabajadores

27 K. Marx (1977) y F. Engels (1895).

28 Hacemos referencia aquí a la teoría de la acumulación desarrollada por Karl Marx en la séptima sección del primer libro de El Capital (Marx, 1950: 7-151). 
deben disponer de una parte de sus ganancias para pagar en un futuro más o menos cercano la indemnización de expropiación de la empresa.

De esta manera, al no poder invertir en nuevas tecnologías que permitan aumentar la productividad, los trabajadores solo disponen de un factor con el cual aumentar la tasa de ganancia: trabajar más.

Si bien el trabajo es creador de valor de la mercancía, este valor está determinado por el tiempo socialmente necesario a su producción. ${ }^{29}$ La introducción de nuevas tecnologías en una rama industrial determinada, induce a una disminución del tiempo necesario para la producción de la mercancía, lo cual implica una depreciación de su valor. ${ }^{30}$

Los precios de las mercancías (de igual categoría) se determinan por su valor social, el cual depende de las condiciones medias de producción de la rama industrial a la que pertenezcan. Pero dado que las condiciones en las que las empresas producen son desiguales, los valores individuales de sus productos también lo son (Marx, 1978:188-198).

Frente a la disminución progresiva del valor social de las mercancías, inducida por la aplicación de métodos para intensificar el trabajo y la introducción de nuevas tecnologías para aumentar la productividad, las ER solo pueden sobrevivir aumentando la intensidad y/o prolongando el tiempo de trabajo. ${ }^{31}$

Si bien en las empresas observadas, los trabajadores no sobrepasan de manera permanente ni los ritmos de trabajo ni el horario semanal

29 El tiempo socialmente necesario a la producción de una mercancía es el tiempo medio de trabajo necesario a la producción de esta, según el desarrollo social de las fuerzas productivas (Marx, 1978: 188-198).

30 Este fenómeno responde a la competencia entre capitalistas de un mismo sector.

31 El impacto es más fuerte en las empresas que pertenecen a sectores de mayor capital constante que en aquellas pertenecientes a sectores con menor dependencia de tecnología (como es el caso de algunos servicios o de producción artesanal y semi-artesanal) así como también en las empresas pertenecientes a sectores de producción de bienes raros o en las cuales existe escasez por razones de contexto económico en el cual la demanda se intensifica (Négation, 1974). 
normal (el cual ronda las cuarenta horas semanales), ${ }^{32}$ se observa que, a medida que los trabajadores avanzan en la consolidación económica de la empresa, los procesos de autogestión y solidaridad establecidos desde los días de lucha ceden el lugar a cuestiones vinculadas a la producción y al mercado.

Así por ejemplo, Alba (trabajadora de Brukman) plantea en relación a la participación en las luchas de otros trabajadores y el desarrollo de una escuela de oficio dentro de la fábrica, como existía durante el primer tiempo de lucha por la recuperación:

... por el momento no se puede. No podes estar produciendo y haciendo una etapa cuando estás queriendo iniciar otra (...) A nosotros todavía nos falta mucho para organizarnos en cooperativa. Es todo un proceso. ${ }^{33}$

De esta forma, se confirma lo señalado por Marx hace más de un siglo atrás: al conformar una cooperativa de trabajo, "la contradicción entre capital y trabajo" es abolida, pero los trabajadores son, "en tanto que asociación, su propio capitalista, es decir, emplean los medios de producción para valorizar su propio trabajo" (Marx, 1970: 105).

Dado que para aumentar la producción los trabajadores disponen casi exclusivamente de su fuerza de trabajo, la solidaridad hacia otras luchas y la participación y toma de decisiones colectiva a partir de la asamblea general se convierten en un obstáculo a la productividad. En efecto, estos procesos de solidaridad y autogestión requieren de tiempo. Pero el tiempo es indispensable para la creación de valor de sus mercancías. En un sistema de racionalización empresarial (necesaria a la sobrevivencia de la empresa), el tiempo debe ser utilizado para la prolongación de la jornada laboral y/o para el descanso necesario para la reproducción de la fuerza de trabajo.

32 Si bien, algunas ER (como el caso de Brukman, citado previamente) deben intensificar las cadencias de trabajo y/o prolongar el tiempo de la jornada laboral, estos ritmos no son permanentes sino que corresponden a ciertos períodos en los que la demanda aumenta. En el sector textil, estos períodos corresponden al cambio de temporada. 
Para evitar este destino, la Coordinadora de Fábricas Ocupadas y en Lucha reivindicaba la estatización bajo control obrero de las fábricas.

Actualmente, solo los trabajadores de FaSinPat (la ex empresa de Cerámicas Zanón) continúan reivindicando este objetivo, pero en la práctica debieron conformarse en cooperativa de trabajo para evitar el desalojo.

Frente a la competencia de mercado, los trabajadores deben redoblar los esfuerzos para consolidar económicamente la fábrica y mantener, al mismo tiempo, los lazos de solidaridad.

Hasta la actualidad FaSinPat ha logrado enfrentar esta dualidad. Hay que subrayar que Zanón era una de las empresas de cerámicos más grandes y modernas de América Latina, su composición tecnológica le ha permitido posicionarse frente al mercado con más facilidad que otras ER. Sin embargo, a más de nueve años de su recuperación la estructura de FaSinPat comienza a envejecer frente a las nuevas tecnologías introducidas en las grandes empresas de este sector. Este proceso crea una desvalorización del producto que los trabajadores de FaSinPat comienzan a sentir severamente, lo cual induce a reforzar los esfuerzos de productividad que progresivamente podrían terminar desplazando los lazos de solidaridad y la autonomía que estos trabajadores fueron construyendo a lo largo de su lucha.

Respecto a este proceso de las ER, Raúl Godoy (trabajador de FaSinPat) sintetiza:

Lo más importante de esta lucha es, como dijo Celia de Brukman, que pone de manifiesto que si los obreros podemos gestionar una fábrica también podemos gestionar un país (...) La recuperación de las empresas no es una solución definitiva al mercado capitalista en el cual estamos inmersos y en el cual estamos obligados a comprar y a vender nuestros productos. Pero somos un punto de apoyo importante para luchar por algo mayor. ${ }^{34}$ 


\section{Conclusiones}

El ciclo de lucha abierto a finales de los noventa se caracterizó por la presencia y el fortalecimiento de movimientos que apuntaban a la 'autonomía'. A partir de 2003 el capitalismo logra reposicionarse resolviendo la crisis. Se introdujeron mecanismos de dominación que apuntaron a desarticular lazos y saberes construidos en la lucha, los que tuvieron fuerte impacto para los trabajadores de ER. Institucionalizando los mecanismos de recuperación de empresas y condicionando el modo en que los trabajadores deben organizar la cooperativa, el poder estatal respondió a las necesidades más urgentes de los trabajadores reforzando las tensiones internas, desarticulando las solidaridades construidas e interrumpiendo los aprendizajes de organización y gestión iniciados en la lucha, logrando de esta forma su objetivo: controlar con mayor facilidad el proceso de este movimiento.

Al institucionalizarse la cooperativización de las ER los trabajadores se van orientando progresivamente a consolidar económicamente la empresa. Fenómeno fomentado por las respuestas y las exigencias de los poderes estatales. Así por ejemplo, estos últimos años la mayoría de los gobiernos provinciales han incluido, como condición para la expropiación de una ER la prueba de 'viabilidad económica' de la cooperativa, que potencializa la necesidad de orientar la gestión hacia la rentabilidad económica. Finalmente, al obstaculizar los trámites de expropiación definitiva y al no pagar las indemnizaciones de las empresas expropiadas, la inestabilidad jurídica a la que se somete a estas cooperativas refuerza su vulnerabilidad frente al mercado.

A pesar de la institucionalización y la desarticulación de los movimientos sociales, estas experiencias de lucha trazan nuevas perspectivas para los futuros periodos de ascenso de movilización. Los movimientos sociales que lograron resistir a la institucionalización y desarticulación durante este periodo de repliegue de las luchas, fueron reforzando sus niveles de politización y construyendo lazos de solidaridad y autonomía que conformarán probablemente el germen de las futuras luchas. 


\section{Bibliografía}

\section{Textos}

Castillo, Victoria; Diego Rivas, Sofía Rojo y Sebastián Rotondo. "La creación de nuevas empresas durante la etapa post-convertibilidad (2003-2004): impacto sobre el empleo asalariado registrado", Trabajo, ocupación y empleo. Salarios, empresas y empleo 2003-2006, Serie Estudios N5, Buenos Aires, Ministerio de Trabajo, Empleo y Seguridad Social, septiembre de 2006.

Cotarelo, María Celia y Nicolás Carrera Iñigo. "Sujetos y formas de rebelión e Argentina 1993-2001", 6to Congreso Nacional de estudios del trabajo: Los trabajadores y el trabajo en la crisis, Buenos Aires: Asociación Argentina de especialistas en Estudios del Trabajo (ASET), 13-16 de agosto, 2003.

Etchemendy, Sebastián y Vicente Palermo. "Conflicto y concertación. Gobierno, Congreso y organizaciones de interés en la reforma laboral del primer gobierno de Menem (1989-1995)”, Desarrollo económico №148, vol.37, Buenos Aires: Instituto de desarrollo económico y social, enero/ marzo de 1998.

Engels, Friedrich. "Complément et supplément au libre III du Capital”, Marx, Karl, (1969), Le Capital, Livre Troisième, Tome I, Paris : Éditions Sociales, edición $\mathrm{N}^{\circ}$ 1244. 1895

Ferreres, Orlando, J. et al. Dos siglos de economía argentina (1810-2004): Historia argentina en cifras, Buenos Aires: Fundación Norte y Sur, 2005.

Godio, Julio. Historia del movimiento obrero argentino 1870-2000, Tomo II. La época de hegemonía del sindicalismo peronista (1943-2000), Buenos Aires: Ediciones Corregidor, 2000.

Instituto Nacional de Estadística y Censo, Anuario estadístico de la República Argentina 2000, Buenos Aires, INDEC, 2000.

Magnani, Esteban. El cambio silencioso. Empresas y fábricas recuperadas por los trabajadores en la Argentina, Buenos Aires: Prometeo libros, 2003.

Mandel, Ernest. Contrôle ouvrier, conseils ouvriers, autogestion, Paris : François Maspero, 1970. 
Manor, James; Robinson Mark y White Gordon. Civil Society and Governance: A Concept Paper, Working paper, Institute of Development Studies, Sussex: University of Sussex, 26 de agosto de 1999.

Marx, Karl. Le Capital. Livre premier, Tome III, Paris, Éditions Sociales, edición $\mathrm{N}^{\circ}$ 1114, 1950.

Marx, Karl. Le Capital. Livre troisième, Tome II, Paris, Éditions Sociales, edición Nº 1454, 1970.

Marx, Karl. Le Capital. Livre premier, Tome II, Paris, Éditions Sociales, edición $\mathrm{N}^{\circ} 1753,1977$.

Marx, Karl. Le Capital. Livre premier, Tome I, Paris : Éditions Sociales, edición $\mathrm{N}^{\circ} 1826,1978$.

MNFRT. Documento que explica el procesos de recuperación de fábricas por parte de los trabajadores, Boletín N², Año I, Número II, Buenos Aires, 2003.

NÉGATION, Lip et la contre-révolution autogestionnaire, Paris, Négation $\mathrm{N}^{\circ} 3,1974$.

Ramonet, Ignacio et al. Le Krach parfait, Crise du siècle et refondation de l'avenir, Paris : Galilée, 2009.

Rébon, Julián. Desobedeciendo al desempleo. La experiencia de las empresas recuperadas, Buenos Aires, Ed. Picaso/ La rosa blindada, Colección Cuaderno de trabajo $\mathrm{N}^{\circ} 2,2004$.

Thompson, Edward, Palmer (1988), Ed. original, The Making of the English Working Class, La formation de la classe ouvrière anglaise, Paris, GallimardLe Seuil, 1963.

\section{Referencias electrónicas}

FACTA, "Rosario fue sede del acto fundacional de la Federación Argentina de Cooperativas de Trabajadores Autogestionados", en Revista Enredando, diciembre 9 de 2006.

$<$ http://www.enredando.org.ar/noticias_desarrollo.shtml? $x=32018>\quad\left[\begin{array}{ll}14 & \text { de }\end{array}\right.$ octubre de 2010]. 
Zibechi, Raúl. La compleja relación entre gobiernos y movimientos, texto leído en el Festival de la Digna Rabia, Lienzo Charro, México D. F., 28 de enero de 2008, tomado de Programa de las Américas, 2009.

$<$ http://www.ruthcuadernos.org/readarticle.php?article_id=173\&num_id=4 > [19 de octubre de 2010].

Envío 1 de marzo/2011- Aceptación 16 de mayo de 2011 